\title{
NOTES UPON THE INTERCOSTAL ARTERIES IN SOME SNAKES
}

\author{
by \\ L. D. BRONGERSMA \\ Rijksmuseum van Natuurlijke Historie, Leiden
}

From its origin, the right aortic arch passes anteriorly, and obliquely to the right; in this part of its course it gives off the two carotid arteries, or as the case may be (e.g., in Uropeltis melanogaster (Gray)) the common carotid trunk. It then curves dorsally, medially, and caudally. At the end of the dorsal curve, the right aortic arch gives off the vertebral artery, which runs cranially, close to the ventral surface of the vertebral column, to enter the parietes at a greater or smaller distance behind the head. In its further course, the right aortic arch fuses with the left aortic arch to form the dorsal aorta, which passes caudally close to the ventral surface of the vertebral column. The intercostal arteries arise from the vertebral artery, from the right aortic arch (between the origin of the vertebral artery and the fusion of the two aortic arches), and from the dorsal aorta. These intercostal arteries pass dorsally, and they enter the parietes in varying ways, as has been described by BEDDARD $(1903 ; 1904 a, b ; 1906 a, b ; 1908 ; 1909)$ in a series of papers on the anatomy of snakes. This author has pointed to the possible taxonomic value of the differences shown by the various genera and species, which he examined. However, before definite conclusions can be drawn, it will be necessary to examine more genera and species. Studying the intercostal arteries of snakes is time-consuming; their number may be very high (e.g., 156 in a specimen of Xenopeltis unicolor Reinw.), and every artery has to be checked, because various types of intercostal arteries may occur in one individual.

The following types of intercostal arteries can be distinguished.

1. Single arteries, which enter the parietes in the median line.

2. Single arteries, which enter the parietes either to the right or to the left of the vertebral column.
3. Bifurcating arteries, which arise as a single vessel, but which divide into two branches, the one branch entering the parietes to the right, the other to the left of the vertebral column.

4. Longitudinally branching arteries, which arise as a single vessel, but which give off branches which pass cranially or caudally, and the ramifications of which enter the parietes in the median line.

5. Anastomosing arteries, which arise at some distance from each other as single vessels, and which divide into a cranial and a caudal branch; the caudal branch of the one artery is connected to the cranial branch of the next artery, and thus a longitudinal vessel is formed parallel to the vessel (vertebral artery, aorta) which gives off the arteries. From this longitudinal artery, paired arteries arise, and pass into the parietes to the right and left of the vertebrae.

6. Paired arteries, which arise side by side from the vertebral artery or from the aorta, and the one of which enters the parietes to the right, the other to the left of the vertebral column.

In some species the number of intercostal arteries corresponds to the number of vertebrae, in others the interspaces are equal to two or more vertebrae.

In the present notes the intercostal arteries of a small number of species from various families are described to add data to those published by BEDDARD. It is hoped that further notes will be published in the future, and that in this way it will become possible to evaluate the taxonomic importance of the diversity shown by these arteries in snakes. 


\section{TYPHLOPIDAE}

\section{Typhlops diardii mülleri Schl.}

This species shows three types of intercostal arteries, viz., the types 2,3 and 6 mentioned above.

The first two intercostals to arise from the vertebral artery are of the bifurcate type (3); cranially of these the majority of the arteries are single (2), more or less regularly, alternatingly going to the right or to the left of a vertebra. Occasionally a bifurcating artery occurs between the single ones.

But two intercostals arise from the very short right aortic arch; the first is bifurcate, the second is single (2). The series of intercostals arising from the dorsal aorta can be divided into five parts. In the first part of this series, the intercostals are single, regularly alternating on the right and left; one to each vertebra. The second part of the series (at the level of the caudal half of the liver) is formed by bifurcate arteries (3), arising at interspaces. of two vertebrae (rarely with an interspace of but one vertebra); occasionally a few single arteries or paired arteries occur between the bifurcate vessels. The third part of the series (caudally of the liver) consists of single arteries, regularly alternating, and arising at interspaces of one vertebra. More caudally, the fourth part of the series is formed by bifurcating arteries, whilst the fifth part again consists of single, alternating arteries (with an occasional bifurcating artery intercalated between the single ones).

All single arteries arise at intervals of one vertebra; the bifurcating arteries show interspaces of two vertebrae, except where they follow or precede a single artery, from which they are separated by but one vertebra.

\section{LEPTOTYPHLOPIDAE}

\section{Leptotyphlops dulcis (Bd. \& Gir.)}

Only one specimen was available, and I did not succeed in checking the intercostals arising from the vertebral artery.

Two intercostals arise from the right aortic arch; the first of these is single (2), and it enters the parietes to the right of a vertebra; the second intercostal bifurcates before entering the parietes.

The series of intercostals arising from the dorsal aorta can be divided into three parts. The first of these parts consists of single arteries entering the parietes to the right or to the left of the vertebral column; the interspaces are irregular in length. At the level of the kidneys, the intercostals bifurcate before entering the parietes. More caudally, the inter- costals are single again, alternating on the right and left; the intervals are equal to the length of three or four vertebrae.

\section{ANILIIDAE}

Anilius scytale (L.)

BEDDARD (1906. pp. 33, 34) described the intercostals of this species as being all of the bifurcating type, but in the specimens examined by me, I found bifurcate (3), paired (6), and single (2) arteries. All intercostals are regularly interspaced at intervals of one vertebra each.

All intercostals arising from the vertebral artery are of the bifurcating type. From the right aortic arch six bifurcating arteries arise. The majority of the intercostals given off by the dorsal aorta are of the bifurcating type, but halfway down the liver a series of paired intercostals is found.

Cylindrophis rufus (Laur.) (Fig. 1)

The intercostals arise at regular intervals, one to each vertebra. The first two intercostals given off by the

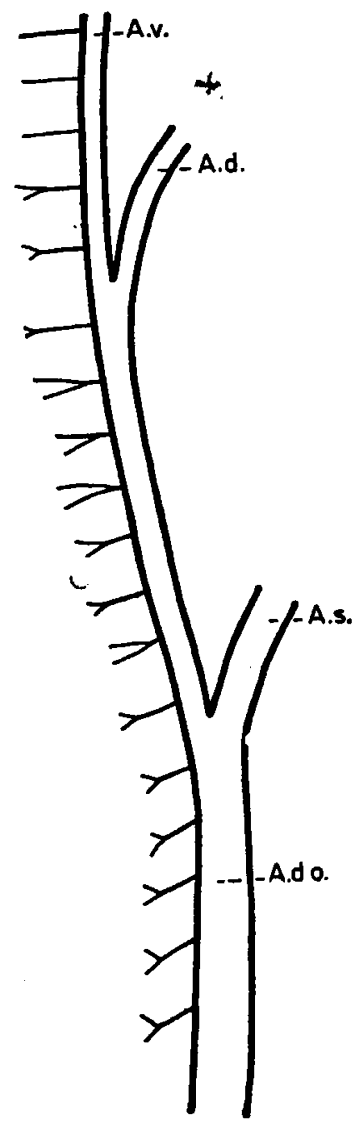

Fig. 1. Cylindrophis rufus (Laur.). A.d., right aortic arch; A.do., dorsal aorta; A.s., left aortic arch; A.v.vertebral artery. 
INTERCOSTAL ARTERIES IN SNAKES

55
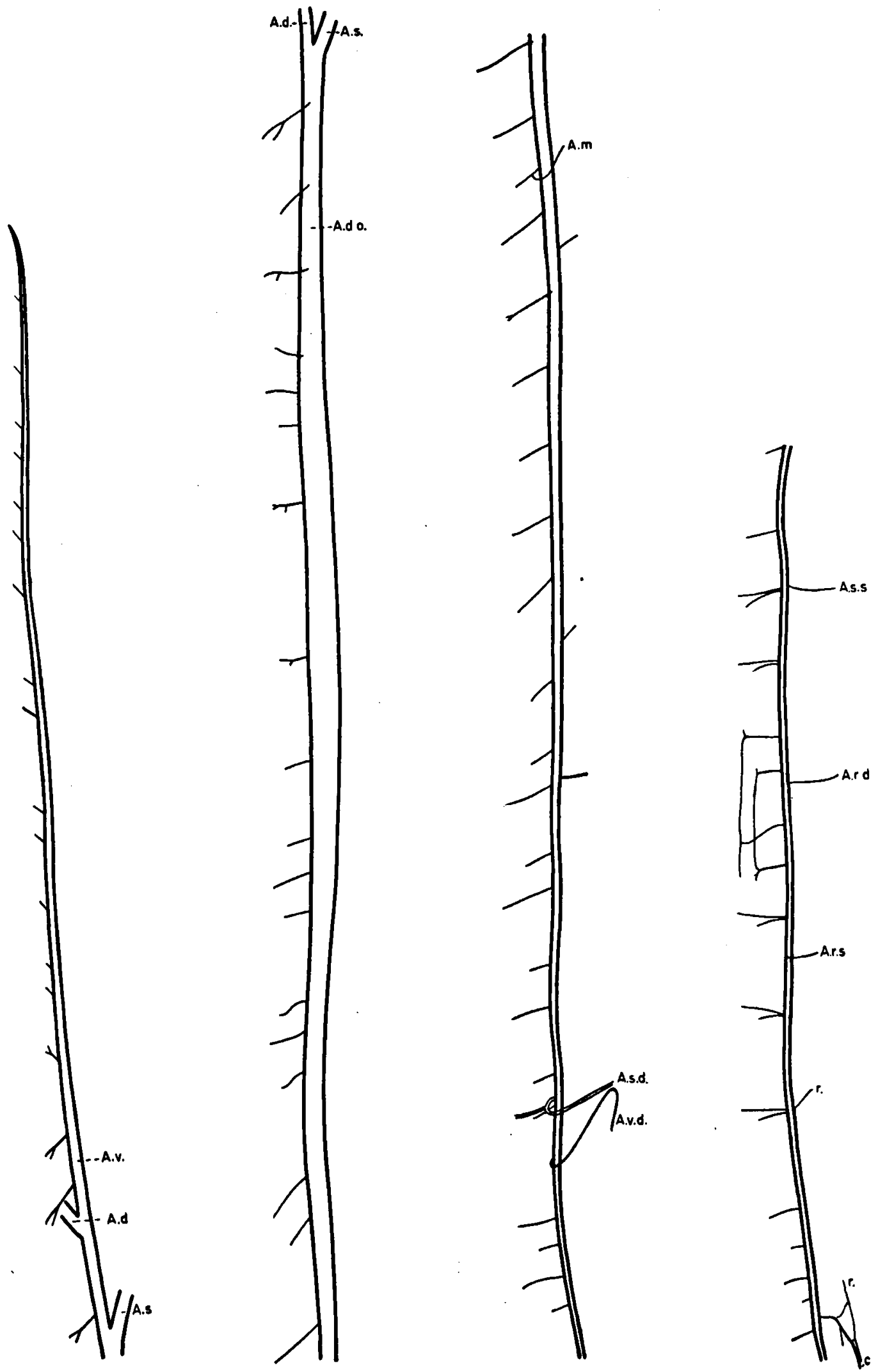

Fig. 2. Uropeltis melanogaster (Gray); Add., right aortic arch; Ado., dorsal aorta; A.m., artery ramifying in mesentery; A.r.d., right renal artery; A.r.s, left renal artery; A.s., left aortic arch; A.s.d., right spermatic artery; A.s.s., left spermatic artery; A.v., vertebral artery; A.v.d.; artery to vas deferent; c. arteries to cloaca; r., arteries to miectúm. ${ }^{\circ 2} 11: 30: 56 \mathrm{AM}$ 
vertebral artery, the eight given off by the right aortic arch, and all those arising from the dorsal aorta bifurcate before they enter the parietes. The third intercostal arising from the vertebral artery, and all those cranially of it, are single, entering the parietes in the median line (type 1).

\section{Anomochilus weberi (Lidth)}

This species was not examined in detail. As far as could be ascertained, the intercostals arising from the right aortic arch, and those given off by the dorsal aorta are regularly spaced at intervals of one vertebra each; they bifurcate close to the vertebral column.

\section{UROPELTIDAE}

Uropeltis melanogaster (Gray) (Fig. 2)

In this species four types of intercostals $(1,2,3,6)$ are present.

The first three intercostals arising from the vertebral artery are bifurcate; the further fifteen intercostals given off by the vertebral artery are single, and they enter the parietes in the median line. The right aortic arch gives off but one, bifurcating artery. The majority of the intercostals arising from the dorsal aorta are single (2), regularly alternating on the right or left, but irregularly spaced at intervals of one or two vertebrae. Towards the caudal end of the series a few paired intercostals occur.

Two of the intercostals give off ramifications to the viscera. The first of these (fig. 2, A.m.) ramifies in the mesentery, and it sends branches to the liver, and to the intestine. The second (fig. 2, A.s.d.) gives off the right spermatic artery. At the level of the right kidney it appears as if two consecutive intercostals, which pass to the right parietes, are connected by a very narrow longitudinal vessel; the same applies to two intercostals, which go to the left parietes, but I must point out that I am not absolutely certain whether this observation is correct, and I have no other suitable specimen to check it.

The distribution of the intercostals from which they arise, is indicated in fig. 2, in which the interspaces are drawn to scale.

\section{XENOPELTIDAE}

Xenopeltis unicolor Reinw.

The intercostal arteries are regularly spaced, at intervals of one vertebra each. The first intercostal to arise from the vertebral artery is bifurcate, those cranially of it are single, entering the parietes in the median line; in a specimen of which the length of head and body is $555 \mathrm{~mm}$, the vertebral artery enters

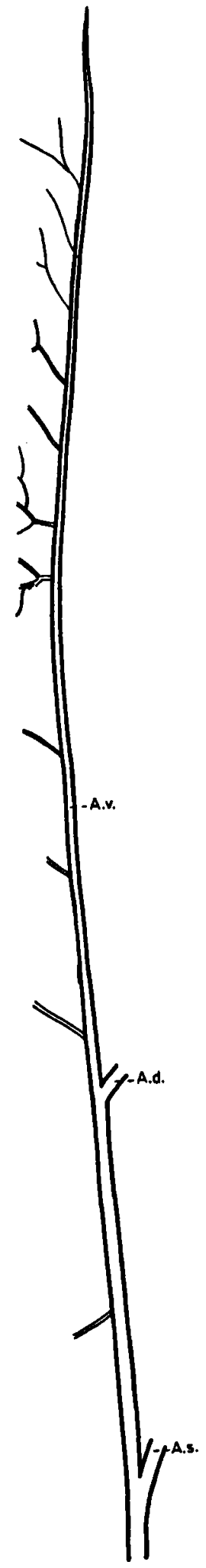

Fig. 3. Homalopsis buccata (L); a, right aorta and vertebral artery; A.d., right aortic arch; A.s., left aortic arch; A.v., vertebral artery. 


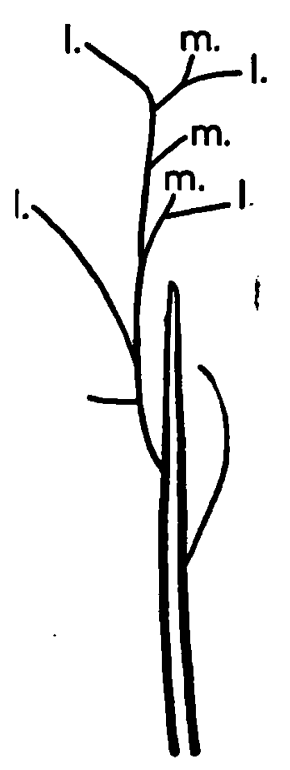

Fig. 4. Homalopsis buccata (L.); cranial end of vertebral artery; l. ramifications going to the lateral surfaces; $\mathrm{m}$., ramifications entering the parietes in the median line.

the parietes at a distance of $52.5 \mathrm{~mm}$ caudally of the tips of the snout. Seven bifurcate intercostals are given off by the right aortic arch. From the dorsal aorta arise a series of bifurcate arteries, but from the level of the gall bladder ( $52 \mathrm{~mm}$ caudally of the liver) towards the end of the series the intercostals are paired.

\section{COLUBRIDAE}

\section{HOMALOPSINAE}

Homalopsis buccatus (L.) (Figs. 3, 4)

Besides single, median intercostals (1), this species shows longitudinally branching intercostals (4). The last mentioned type is found among the intercostals that arise from the vertebral artery (fig. 3), and one of the intercostals arising from the dorsal aorta is of this type. The ramifications of these branching arteries enter the parietes in the median lines at interspaces of one vertebra each. The interspaces between the twenty one intercostals, which arise from the dorsal aorta are irregular, varying from one to nine vertebrae viz. $5,3,8,5,4,7,3,4,6,2,2,3,4,4$, $3,5,2,4,1,6,9,5$ vertebrae.

Just caudally of the point, where the vertebral artery enters the parietes, a very narrow artery arises from it. This narrow artery passes anteriorly, and it gives off three rami which enter the parietes in the median line, and some rami that pass to the left and right parietes (fig. 4).

The fifth type of intercostal arteries mentioned above (i.e. arteries of which the branches join to form a longitudinal vessel below the vertebral column) has been described in various Boidae by BEDDARD (1904a, p. $362 ; 1904$ b, p. 108, fig. 19; 1906b, p. $517 ; 1908$. p. 143); this type also is found in the genera Tropidophis and Trachyboa (Brongersma, 1951, pp. 112 113, fig. 2a, p. 121).

\section{REFERENCES}

Beddard, F. E., 1903: On the Trachea, Lungs, and other Points in the Anatomy of the Hamadryad Snake (Ophiophagus bungarus). Proc. Zool. Soc. Lond., vol. 2, pp. 319-328, textfigs. 36-40.

BedDard, F. E., 1904a: Contributions to our Knowledge of the Circulatory System in the Ophidia, Proc. Zool. Soc. Lond., vol. 1, pp. 331-370, text-figs. 67-78.

Beddard, F. E., 1904b: Notes upon the Anatomy of certain Snakes of the Family Boidae. Proc. Zool. Soc. Lond., vol. 2, pp. 107-121, text-figs. 19-23.

Beddard, F. E., 1906a: Contributions to the Anatomy of the Ophidia. Proc. Zool. Soc. Lond., vol. 1, pp. 12-44, text-figs. 2-11.

Bedparn, F. E., 1906b: Contributions to the Knowledge of the Vascular and Respiratory Systems in the Ophidia, and to the Anatomy of the Genera Boa and Corallus. Proc. Zool. Soc. Lond., vol. 2, pp. 499-532, text.-figs. 86-93.

Beddard, F. E., 1908: A Comparison of the Neotropical Species of Corallus, C. cookii, with Corallus madagascariensis; and on some Points in the Anatomy of Corallus caninus. Proc. Zool. Soc. Lond., pp. 135-158 text.figs. 21-27.

BedDARD, F. E., 1909: Some Notes upon Boa occidentalis and Boa (Pelophilus) madagascariensis. Proc. Zool. Soc. Lond., pp. 918-927, figs. 281-285.

Brongersma, L. D., 1951: Some notes upon the anatomy of Tropidophis and Trachyboa (Serpentes). Zool. Meded. Mus. Leiden, vol. 31, pp. 107-124, figs. 1-8. 